\title{
Adaption to Climate Change through Water Trading under Uncertainty - An Inexact Two-Stage Nonlinear Programming Approach
}

\author{
B. Luo ${ }^{1}$, I. Maqsood ${ }^{1}$, Y. Y. Yin ${ }^{2}$, G. H. Huang ${ }^{1 *}$ and S. J. Cohen ${ }^{2}$ \\ ${ }^{1}$ Environmental Systems Engineering Program, Faculty of Engineering, University of Regina, Regina, SK S4S 0A2, Canada \\ ${ }^{2}$ Adaptation and Impacts Research Group, Environment Canada, Vancouver, BC V6T 1Z2, Canada
}

\begin{abstract}
Shifting hydrological phenomenon under changing climate would lead to decreased water availability, and thus would worse water supply-demand conflicts resulting in penalties on local economy. To tackle water shortage problems, water trading has been proved as an efficient and economical method. However, complexities and uncertainties in water trading system may result in its poor efficiency and improper management. To address these concerns, an inexact two-stage stochastic nonlinear programming (ITSNP) model is proposed for water resources management through water trading under uncertainty. The ITSNP model can reflect nonlinearity of the problems, incorporate uncertainties expressed as probability distributions and discrete intervals, and provide linkages between predefined policies and associated economic implications. The developed model is applied to a case study of water resources management of an agricultural system with and without water trading schemes. The obtained modeling solutions indicate that water resources management is more efficient with water trading than without water trading particularly during dry seasons. Moreover, it is found that water trading is a suitable method for adaptation to climate change impacts under water scarcity.
\end{abstract}

Keywords: Adaptation, climate change, inexact, management, nonlinear, two-stage stochastic, uncertainty, water trade

\section{Introduction}

Impacts of climate change on water supply-demand balance have been concerned in many parts of the world, especially for those located in arid and semi-arid regions (Herrington et al., 1997; Frederick et al., 1999; Lettenmaier et al., 1999; Beuhler, 2003; Merritt et al., 2003; Ojo et al., 2003). Recent studies indicate that probability of low-flow occurrence would increase in most watersheds because of shifting hydrological regime under changing climate. This would result in decreased water availability. At the same time, due to socio-economic development, water consumption would continue to increase to satisfy the escalating demands. This would worse water supply-demand conflicts and result in penalties on local economy. Therefore, there is a need for studies to develop appropriate techniques to tackle future water shortage problems and minimize the associated penalties in response to the climate change impacts (Sefton et al., 1997; Eheart et al., 1999; Mimikou et al., 2000; Chiew et al., 2002).

Without big investment as constructing infrastructure to store enough water, water trading has been proved as an efficient and economical method to handle water shortage problems (Dale, 1968; Anderson, 1983; Berker et al., 1996; Landry et al., 1998). Moreover, water trading has an advantage of releasing water for ecosystem protection and water quality improvement during dry seasons in arid and semi-arid regions (Rosegrant et al., 1995; Tisdell, 2001). In several countries, markets for entitlements to extract water have even been introduced as a mechanism for water redistribution (Dra-

\footnotetext{
* Corresponding author: gordon.huang@uregina.ca
}

gun et al., 1989; Topp et al., 1998; Brennan et al., 1999). However, before building up a water trading system, it is important to estimate the efficiency of the planned trading system and analyze its possible impacts. Previously, a number of studies have been undertaken to investigate the efficiency of water trading (Saliba et al., 1987; Michelsen, 1994; Streeter, 1997). For example, Rosegrant et al. (1995) investigated how to design water rights and supporting institutions to attain the objectives of efficient crop diversification and water use by drawing lessons from case studies in Chile, Mexico, and California; Wollmuth et al. (2000) explored the efficiency of water trading by studying the surface water withdrawal allocation and trading systems for traditionally riparian areas; Tisdell (2001) developed a linear program to analyze the water markets for agricultural water of the Border River in Australia.

However, complexities and uncertainties in water trading problems under changing climate may result in decreased efficiency of the trading systems. For example, it is hard to determine how much extra water should be delivered to satisfy the increasing demands when stream flows are decreasing under climate change impacts. Higher water allocation targets means increased investments in water infrastructure and raised penalties on local economy, when water shortages exist during dry seasons. Conversely, reducing the allocation targets results in lower risk of penalties under water scarcity and a higher risk of water-resources wastage. Such problems can often be formulated as two-stage stochastic programming (TSP) models (Anderson, 1968; Kall, 1979; Louveaux, 1980; Birge, 1985; Birge \& Louveaux, 1988; Gassmann, 1990; Eiger \& Shamir, 1991; Lustig et al., 1991; Sen, 1993; Ediris- 
inghe \& Ziemba, 1994; Ruszczynski \& Swietanowski, 1997; Beraldi et al., 2000; Dai et al., 2000; Darby-Dowman et al., 2000; Yoshitomi et al., 2000; Zhao, 2001). In TSP, a decision is made at the first stage before random variables are known and then, after the random events have happened and their values are known, a second decision should be made in order to minimize penalties that may appear due to any infeasibility (Loucks et al., 1981; Birge et al., 1988; Ruszczynski, 1993). In many real-world problems such as water trading in watersheds, most of available data is generally not of high quality to be presented as probability density distribution (PDF). Thus non-PDF information cannot be directly incorporated within conventional TSP problems. For example, PDF alone may not be capable of reflecting changes in water availability because of shifting hydrologic regime under climate change; rather water availability may be more conveniently represented as intervals. Moreover, it is extremely hard to solve a large-scale TSP model with all uncertain parameters being expressed as PDFs, even if these functions are available. Therefore, an efficient reflection of such uncertainties is critical in estimating the efficiency of a water trading system and analyzing its impacts.

To address such uncertainties in a TSP problem, an inexact two-stage stochastic programming (ITSP) model was introduced by Huang and Loucks (2000). One advantage of the ITSP technique is that it can directly incorporate uncertainties expressed as discrete intervals and probabilities within a TSP framework. Recently, this technique has been successfully extended to deal with the problems of waste and water resources management (Maqsood and Huang 2003; Maqsood et al., 2003). However, relations among parameters in water trading problems can be more complex, which can be better expressed as nonlinearity instead of linearity alone. Thus, it is desired to integrate nonlinear programming into the ITSP framework. This will lead to an inexact two-stage stochastic nonlinear programming (ITSNP) approach.

As an extension of the previous efforts, the objective of this study is to develop an ITSNP model for the management of water trading within an agricultural system under uncertainty. The proposed model will tackle nonlinearities, complexities, and uncertainties in water trading problems. This study will help design efficient water trading system to address water supply-demand conflicts under climate change impacts. The obtained solutions will provide valuable decision support for the management of water resources through water trading.

\section{Modeling Formulation}

Consider a problem in which a water trading system needs to be constructed among multiple users due to decreased water availability and increased water demands under climate change. Currently, water is allocated to these users in proportion to their water permits during dry seasons. By trading, water can be reallocated to its most efficient user. It is needed to know how much water all the users can expect with and without water trading. If insufficient water is available, how water trading will impact the penalties which they will suffer. Thus, the problem can be formulated as maximizing the net benefit for all users in order to maximize benefit of local economy. Given a quantity of water is promised to each user. In addition, various uncertainties exist in the water trading system components such as water-allocation targets, economic data, and water availability. Moreover, relations between reduction in net benefit and water shortage are nonlinear. Since the total water availability is a random variable, the objective function of this problem can be formulated as a two-stage stochastic nonlinear programming (TSNP) model as follows:

$\operatorname{Max} \Psi=\sum_{i=1}^{u} B_{i} X_{i}-E\left[\sum_{i=1}^{u} D_{i} T_{i Q}^{\beta_{i}}\right]$

where $\Psi$ is average net benefit for all users $(\$) ; B_{i}$ is net benefit to user i per $\mathrm{m}^{3}$ water allocated $\left(\$ / \mathrm{m}^{3}\right) ; X_{i}$ is fixed water-allocation target to user $\mathrm{i}\left(\mathrm{m}^{3}\right)$ (first-stage decision variable); $E[x]$ is expected value of a random variable $x ; D_{i}$ is reduction of net benefit to user i per $\mathrm{m}^{3}$ water not delivered $\left(\$ / \mathrm{m}^{3}\right) ; T_{i O}$ is amount by which water-allocation target $X_{i}$ is not met when seasonal flow is $Q\left(\mathrm{~m}^{3}\right) ; Q$ is random variable equal to total water availability $\left(\mathrm{m}^{3}\right) ; \beta_{i}$ is coefficient of water shortage and reduction of net benefit $\left(0<\beta_{i}\right) ; u$ is total number of users.

Since $Q$ is a random variable in model (1), the distribution of $Q$ must be converted to an equivalent set of discrete values in order to solve model (1). Let $Q$ takes values $Q_{j}$ with probabilities $p_{j}$, where $j$ defines $p$ levels of water availability. Model (1) can be reformulated as follows (Loucks, 1981):

$\operatorname{Max} \Psi=\sum_{i=1}^{u} B_{i} X_{i}-\sum_{i=1}^{u} \sum_{j=1}^{v} p_{j} D_{i} T_{i j}^{\beta_{i}}$

where $T_{i j}$ are decision variables representing amount by which water-allocation target is not met to user $i$ when total water availability is $Q_{j}\left(\mathrm{~m}^{3}\right) ; Q_{j}$ is total water availability with probability $p_{j}$ of occurrence $\left(\mathrm{m}^{3}\right) ; p_{j}$ is probability of occurrence under water availability $j(\%) ; j$ is flow level, $j=1$, $2, \ldots, v$.

The above TSNP model can effectively deal with uncertainties presented in random water availability. It can set water-allocation target for each user through its first-stage decision variables $\left(X_{i}\right)$. However, uncertainties may also exist in other parameters such as economic data $\left(B_{i}\right.$ and $\left.D_{i}\right)$ and water-allocation targets $\left(X_{i}\right)$, which generally exist as ambiguous intervals instead of deterministic values. Decision makers may find it harder to specify PDFs than to define fluctuation ranges (Huang \& Loucks, 2000). For instance, water-allocation targets can hardly be expressed as a PDF while it can be easily defined as an interval. Water availability can be expressed as not only a PDF, but also interval value. To reflect such uncertainties, interval parameters (Huang et al., 1993) can therefore be introduced into model (2), resulting in an inexact two-stage nonlinear programming (ITSNP) model: 
$\operatorname{Max} \Psi^{ \pm}=\sum_{i=1}^{u} B_{i}^{ \pm} X_{i}^{ \pm}-\sum_{i=1}^{u} \sum_{j=1}^{v} p_{j} D_{i}^{ \pm}\left(T_{i j}^{ \pm}\right)^{\beta_{i}}$

where '-' and '+' superscripts represent the lower and upper bounds of the parameters, respectively. Traditionally, authorities allocate water to users with respect to their permits if available water is insufficient during dry seasons. Thus, according to model (3), the average net benefit without water trading can be obtained though the objective function as follows:

$\operatorname{Max} \bar{\Psi}_{1}^{ \pm}=\sum_{i=1}^{u} B_{i}^{ \pm} X_{i}^{ \pm}-\sum_{i=1}^{u} \sum_{j=1}^{v} p_{j} D_{i}^{ \pm}\left(T_{i j}^{ \pm}\right)^{\beta_{i}}$

\section{Constraints:}

(1) Relaxed constraints for water permits: The constraints describe that total expected water demand for each user is less than or equal to user's water permit.

$$
X_{i}^{ \pm} \leq \tilde{W}_{i}, \quad \forall j
$$

(2) Relaxed constraints for water violation: The constraints ensure that the amount by which water-allocation target is not met is less than or equal to the allocation target.

$$
0 \leq T_{i j}^{ \pm} \leq X_{i}^{ \pm}, \quad \forall i, j
$$

(3) Relaxed constraints for water allocation in a dry seasons: The constraints reflect that water should be proportionally allocated to users according to their issued permits before water trading when water availability is inadequate for all users.

$$
X_{i}^{ \pm}-T_{i j}^{ \pm}=\frac{\tilde{W}_{i}}{\sum_{i} \tilde{W}_{i}} Q_{j}^{ \pm}, \text {if } \sum_{i=1}^{m} \tilde{W}_{i} \geq Q_{j}^{ \pm}, \quad \forall j
$$

(4) Relaxed constraint when total water availability is sufficient.

$$
X_{i}^{ \pm}-T_{i j}^{ \pm}<\frac{\widetilde{W}_{i}}{\sum_{i} \widetilde{W}_{i}} Q_{j}^{ \pm}, \text {if } \sum_{i=1}^{m} \widetilde{W}_{i}<Q_{j}^{ \pm}, \forall j
$$

where $\bar{\Psi}_{1}^{ \pm}$is average net benefit without water trading (\$); $\tilde{W}_{i}$ is water permit to user $\mathrm{i}\left(\mathrm{m}^{3}\right) ; Q_{j}^{ \pm}$is total water availability with probability $p_{j}$ of occurrence $\left(\mathrm{m}^{3}\right)$. When water is tradable, all users are no longer constrained by their own water permits but theoretically by the aggregate supply of total water availability. Thus, average net benefit for all users $\left(\bar{\Psi}_{2}^{ \pm}\right)$ can be estimated by the objective function as follows:
$\operatorname{Max} \bar{\Psi}_{2}^{ \pm}=\sum_{i=1}^{u} B_{i}^{ \pm} X_{i}^{ \pm}-\sum_{i=1}^{u} \sum_{j=1}^{v} p_{j} D_{i}^{ \pm}\left(T_{i j}^{ \pm}\right)^{\beta_{i}}$

\section{Constraints:}

(1) Relaxed constraints for water permits: These constraints ensure that the water-allocation targets for each user are not constrained by their own permits when water is tradable.

$$
\sum_{i=1}^{u} X_{i}^{ \pm} \leq \sum_{i=1}^{m} \tilde{W}_{i}, \quad \forall j
$$

(2) Relaxed constraints for water violation

$0 \leq T_{i j}^{ \pm} \leq X_{i}^{ \pm}, \quad \forall i, j$

(3) Relaxed constraints for water reallocation: When water is tradable, water can be reallocated to its most efficient user instead of proportionally distributed to each user according to their permits.

$\sum_{i=1}^{u}\left(X_{i}^{ \pm}-T_{i j}^{ \pm}\right) \leq Q_{j}^{ \pm}, \quad \forall j$

Models (4) and (5) both form an inexact two-stage stochastic nonlinear programming model without water trading and with water trading, respectively. They can deal with nonlinearities and uncertainties. When $X_{i}^{ \pm}$are known, each of them can be transformed into two deterministic nonlinear submodels, which correspond to the lower and upper bounds of the desired objective function (Huang, 1996). Since $X_{i}^{ \pm}$is considered as inexact inputs in the ITSNP model, the existing methods for solving interval programming problems cannot be used directly.

According to Huang and Loucks (2000), let $X_{i}^{ \pm}=X_{i}^{-}+\lambda_{i}\left(X_{i}^{+}-X_{i}^{-}\right)$, where $\lambda_{i} \in[0,1]$. When $\lambda_{i}$ is equal to $1, X_{i}^{ \pm}$approach their upper bounds, and it is assumed that the average net benefit will be the highest as long as the water demands are well satisfied; however, this is associated with a higher risk of penalty when the promised amount of water is not delivered. Conversely, when $\lambda_{i}$ is equal to $0, X_{i}^{ \pm}$ reach their lower bounds, this will lead to a lower average net benefit and a lower risk of violating the promised amounts.

Thus, here $\lambda_{i}$ is a set of decision variables. A set of target values can be optimized by having $\lambda_{i}$ in models (4) and (5) as decision variable. Thus, by incorporating values of $X_{i}^{ \pm}$into model (5), we have:

$\operatorname{Max} \bar{\Psi}_{1}^{ \pm}=\sum_{i=1}^{u} B_{i}^{ \pm}\left[X_{i}^{-}+\lambda_{i}\left(X_{i}^{+}-X_{i}^{-}\right)\right]$ 


$$
-\sum_{i=1}^{u} \sum_{j=1}^{v} p_{j} D_{i}^{ \pm}\left(T_{i j}^{ \pm}\right)^{\beta_{i}}
$$

subject to:

$$
\begin{aligned}
& X_{i}^{-}+\lambda_{i}\left(X_{i}^{+}-X_{i}^{-}\right) \leq \tilde{W}_{i}, \quad \forall j \\
& -\lambda_{i}\left(X_{i}^{+}-X_{i}^{-}\right)+T_{i j}^{ \pm} \leq X_{i}^{-}, \quad \forall i, j \\
& \lambda_{i}\left(X_{i}^{+}-X_{i}^{-}\right)-T_{i j}^{ \pm}=\frac{\tilde{W}_{i}}{\sum_{i} \tilde{W}_{i}} Q_{j}^{ \pm}-X_{i}^{-},
\end{aligned}
$$$$
\text { if } \sum_{i=1}^{m} \tilde{W}_{i} \geq Q_{j}^{ \pm}, \quad \forall j
$$

$X_{i}^{-}+\lambda_{i}\left(X_{i}^{+}-X_{i}^{-}\right)-T_{i j}^{ \pm}<\frac{\widetilde{W}_{i}}{\sum_{i} \widetilde{W}_{i}} Q_{j}^{ \pm}$,

if $\sum_{i=1}^{m} \widetilde{W}_{i}<Q_{j}^{ \pm}, \quad \forall j$

$$
T_{i j}^{ \pm} \geq 0, \forall i, j
$$

$0<\lambda_{i} \leq 1, \quad \forall i$

Since the objective is to maximize average net benefit for all users, the objective function value corresponding to $\bar{\Psi}_{1}^{+}$is desired. A combination of the upper bounds for benefit coefficients and decision variables and the lower bounds for cost terms would correspond to $\bar{\Psi}_{1}^{+}$. Thus, the submodel corresponding to $\bar{\Psi}_{1}^{+}$can be expressed as:

$$
\begin{aligned}
\operatorname{Max} \bar{\Psi}_{1}^{+}= & \sum_{i=1}^{u} B_{i}^{+}\left[X_{i}^{-}+\lambda_{i}\left(X_{i}^{+}-X_{i}^{-}\right)\right] \\
& -\sum_{i=1}^{u} \sum_{j=1}^{v} p_{j} D_{i}^{-}\left(T_{i j}^{-}\right)^{\beta_{i}}
\end{aligned}
$$

subject to:

$$
\begin{aligned}
& X_{i}^{-}+\lambda_{i}\left(X_{i}^{+}-X_{i}^{-}\right) \leq \tilde{W}_{i}, \quad \forall j \\
& -\lambda_{i}\left(X_{i}^{+}-X_{i}^{-}\right)+T_{i j}^{-} \leq X_{i}^{-}, \quad \forall i, j \\
& \lambda_{i}\left(X_{i}^{+}-X_{i}^{-}\right)-T_{i j}^{-}=\frac{\tilde{W}_{i}}{\sum_{i} \tilde{W}_{i}} Q_{j}^{+}-X_{i}^{-}, \\
& \text {if } \sum_{i=1}^{m} \tilde{W}_{i} \geq Q_{j}^{+}, \quad \forall j \\
& X_{i}^{-}+\lambda_{i}\left(X_{i}^{+}-X_{i}^{-}\right)-T_{i j}^{ \pm}<\frac{\widetilde{W}_{i}}{\sum_{i} \widetilde{W}_{i}} Q_{j}^{ \pm},
\end{aligned}
$$

$$
\begin{aligned}
& \text { if } \sum_{i=1}^{m} \widetilde{W}_{i}<Q_{j}^{ \pm}, \quad \forall j \\
& T_{i j}^{-} \geq 0, \quad \forall i, j \\
& 0<\lambda_{i} \leq 1, \quad \forall i
\end{aligned}
$$

where $T_{i j}^{-}$and $\lambda_{i}$ are decision variables. Submodel (7) is a deterministic nonlinear programming problem. Let $T_{i j(l)}^{-}$and $\lambda_{i(1)}$ be the optimized solutions of submodel (7). Then, the optimized water-allocation target for each user can be performed by calculating $X_{i(l)}^{ \pm}=X_{i}^{-}+\lambda_{i(l)}\left(X_{i}^{+}-X_{i}^{-}\right)$, which corresponds to the extreme upper bound of system benefit under uncertain inputs of water allocation amounts. The submodel corresponding to $\bar{\Psi}_{1}^{-}$can be formulated as follows:

$\operatorname{Max} \bar{\Psi}_{1}^{-}=\sum_{i=1}^{u} B_{i}^{-} X_{i(l)}^{ \pm}-\sum_{i=1}^{u} \sum_{j=1}^{v} p_{j} D_{i}^{+}\left(T_{i j}^{+}\right)^{\beta_{i}}$

subject to:

$-\lambda_{i(l)}\left(X_{i}^{+}-X_{i}^{-}\right)+T_{i j}^{+} \leq X_{i}^{-}, \quad \forall i, j$

$X_{i(l)}^{ \pm}-T_{i j}^{+}=\frac{\tilde{W}_{i}}{\sum_{i} \tilde{W}_{i}} Q_{j}^{-}$, if $\sum_{i=1}^{m} \tilde{W}_{i} \geq Q_{j}^{-}, \quad \forall j$

$X_{i(1)}^{-}-T_{i j}^{+}<\frac{\widetilde{W}_{i}}{\sum_{i} \widetilde{W}_{i}} Q_{j}^{-}$, if $\sum_{i=1}^{m} \widetilde{W}_{i}<Q_{j}^{ \pm}, \quad \forall j$

$T_{i j}^{+} \geq T_{i j(l)}^{-}, \quad \forall i, j$

where $T_{i j}^{+}$are decision variables. Submodel (8) is also a deterministic nonlinear problem and its solution is similar to submodel (7). Thus, solutions of model (4) under the optimized water allocation targets are as follows:

$\bar{\Psi}_{1 \text { opt }}^{ \pm}=\left[\bar{\Psi}_{1 \text { opt }}^{-}, \bar{\Psi}_{1 \text { opt }}^{+}\right]$

$T_{i j(1)}^{ \pm}=\left[T_{i j(1)}^{-}, T_{i j(1)}^{+}\right], \forall i, j$

where $\bar{\Psi}_{1 \text { lopt }}^{-}$and $T_{i j(l)}^{-}$are from solution of submodel (7), and $\bar{\Psi}_{\text {lopt }}^{+}$and $T_{i j(l)}^{+}$are from solution of submodel (8). Thus, the optimum water allocation scheme to each user under different probabilities of water availability is:

$A_{i j(1)}^{ \pm}=X_{i j(1)}^{ \pm}-T_{i j(l)}^{+}, \quad \forall i, j$

Similarity, model (5) can be solved the same as model (4). Solutions of model (5) are as follows: 


$$
\begin{aligned}
& X_{i(2)}^{ \pm}=X_{i}^{-}+\lambda_{i(2)}\left(X_{i}^{+}-X_{i}^{-}\right) \\
& \bar{\Psi}_{2 \text { opt }}^{ \pm}=\left[\bar{\Psi}_{2 \text { opt }}^{-}, \bar{\Psi}_{2 \text { opt }}^{+}\right] \\
& T_{i j(2)}^{ \pm}=\left[T_{i j(2)}^{-}, T_{i j(2)}^{+}\right], \quad \forall i, j \\
& A_{i j(2)}^{ \pm}=X_{i j(2)}^{ \pm}-T_{i j(2)}^{+}, \quad \forall i, j
\end{aligned}
$$

When the water-allocation target and allocation scheme have been set, each user's net benefit under probability of occurrence $p_{j}$ can be obtained. For model (4), they can be calculated by:

$$
\begin{aligned}
& \Psi_{i j(1)}^{ \pm}=\left[\Psi_{i j(l)}^{-}, \Psi_{i j(l)}^{+}\right], \quad \forall i, j \\
& \Psi_{i j(1)}^{+}=B_{i}^{+} X_{i(l)}^{ \pm}-D_{i}^{-}\left(T_{i j(l)}^{-}\right)^{\beta}, \quad \forall i, j \\
& \Psi_{i j(1)}^{-}=B_{i}^{-} X_{i(l)}^{ \pm}-D_{i}^{+}\left(T_{i j(l)}^{+}\right)^{\beta}, \quad \forall i, j
\end{aligned}
$$

For model (5), they are:

$$
\begin{aligned}
& \Psi_{i j(2)}^{ \pm}=\left[\Psi_{i j(I)}^{-}, \Psi_{i j(I)}^{+}\right], \quad \forall i, j \\
& \Psi_{i j(2)}^{+}=B_{i}^{+} X_{i(2)}^{ \pm}-D_{i}^{-}\left(T_{i j(2)}^{-}\right)^{\beta}, \quad \forall i, j \\
& \Psi_{i j(2)}^{-}=B_{i}^{-} X_{i(2)}^{ \pm}-D_{i}^{+}\left(T_{i j(2)}^{+}\right)^{\beta}, \quad \forall i, j
\end{aligned}
$$

Efficiency of water trading is evaluated based on the comparison of net system benefit gained per unit water consumed under different probabilities of water availability as follows:

$$
R_{j(1)}^{ \pm}=\sum_{i=1}^{u} \Psi_{i j(1)}^{ \pm} / \sum_{i=1}^{u} A_{i j(1)}^{ \pm}, \quad \forall j
$$

$$
R_{j(2)}^{ \pm}=\sum_{i=1}^{u} \Psi_{i j(2)}^{ \pm} / \sum_{i=1}^{u} A_{i j(2)}^{ \pm}, \quad \forall j
$$

where $R_{i(1)}^{ \pm}$and $R_{j(2)}^{ \pm}$are the unitary total net benefits when unit water is delivered prior and after trading under different probabilities of water availability $Q_{j}^{ \pm}$, respectively.

\section{Application}

To demonstrate usefulness of the proposed ITSNP modeling approach, it is applied to a semi-hypothetical problem of water trading within an agricultural system in order to evaluate whether water trading is a suitable method as an adaptation option to climate change impacts.

The agricultural system is located in a semi-arid region wherein three farmers plant wheat, bean, and sunflower; each farmer cultivates one type of crop. The farmers extract irrigation water from a local reservoir. The crop types, crop water demand, and related economic data are shown in Table 1 (ICDC, 2003). It is predicted that the probability of low-flow occurrence will increase under climate change, which will lead to decreased irrigation-water availability. It is also predicted that crop water demand will increase approximately $40 \%$ by period $2070-2090$ because of the changing climate (Neilsen et al., 2001). To mitigate the water supply-demand conflict especially during a dry seasons, a water trading system is proposed to be constructed. Before developing such a trading system, it is needed to estimate efficiency of the proposed trading system and analyze its possible impacts on the agricultural system under uncertainties. Table 2 lists the amounts of irrigation water and the associated distributions.

Based on the data shown in Table 1, a nonlinear relationship between reduction of net benefit and water shortage for each crop is developed. This nonlinear relationship is presented in Figure 1 as a monotone increasing curve. This curve indicates that relation between reduction of benefit and water shortage can be viewed as linear when the shortage is low. This implies that the relationship can be considered as linear within an interval. For example, when water shortage is within 0 to $500 \times 10^{3} \mathrm{~m}^{3}$, the relationship can be presented as

Table 1. Agricultural and Economic Data

\begin{tabular}{ccccccc}
\hline Farmer & Crop & $\begin{array}{c}\text { Current crop } \\
\text { water demand } \\
\left(\mathrm{m}^{3}\right)\end{array}$ & $\begin{array}{c}\text { Current gross } \\
\text { benefit } \\
\text { (\$/acre) }\end{array}$ & $\begin{array}{c}\text { Current crop } \\
\text { price (\$/ton) }\end{array}$ & $\begin{array}{c}\text { gross benefit } \\
\text { (\$/acre) }\end{array}$ & $\begin{array}{c}\text { Cropping cost } \\
\text { per unit land } \\
\text { (\$/acre) }\end{array}$ \\
\hline 1 & Wheat & 1250 & {$[2.18,2.45]$} & 132 & {$[288,324]$} & 253 \\
2 & Bean & 850 & {$[1.15,1.4]$} & 505 & {$[580.8,707]$} & 371 \\
3 & Sunflower & 1450 & {$[1.0,1.4]$} & 300 & {$[300,420]$} & 280 \\
\hline
\end{tabular}


Table 2. Irrigation Water and Associated Probabilities

\begin{tabular}{ccc}
\hline $\begin{array}{c}\text { Water availability } \\
\text { level }(J)\end{array}$ & $\begin{array}{c}\text { Probability } \\
\left(p_{j}\right)\end{array}$ & $\begin{array}{c}\text { Total irrigation water } \\
\left(Q_{j}^{ \pm} \times 10^{3} \mathrm{~m}^{3}\right)\end{array}$ \\
\hline 1 & 0.15 & {$[4000,4500]$} \\
2 & 0.2 & {$[[6500,7000]$} \\
3 & 0.3 & {$[9000,10500]$} \\
4 & 0.2 & {$[12000,15000]$} \\
5 & 0.15 & {$[16500,19000]$} \\
\hline
\end{tabular}

linear. In addition, since the fixed water-allocation target $\left(x_{i}^{ \pm}\right)$ is within the boundary values $\left[x_{i}^{-}, x_{i}^{+}\right]$, it is reasonable to construct a linear relation between net benefit $\left(b_{i}^{ \pm}\right)$and the fixed water-allocation target $\left(x_{i}^{ \pm}\right)$. Based on the data provided in Table 1 , the interval values of parameter $b_{i}^{ \pm}$and $d_{i}^{ \pm}$are determined and listed in Table 3. Table 3 also shows water permit data, areas of cropped land, and extra crop water demand of each farmer under climate change.

Thus based on model (4), when water is not tradable, the problem under consideration can be formulated as follows:

$\operatorname{Max} \bar{\Psi}_{1}^{ \pm}=\sum_{i=1}^{u} h_{i} b_{i}^{ \pm} x_{i}^{ \pm}-\sum_{i=1}^{u} \sum_{j=1}^{v} p_{j} h_{i} d_{i}^{ \pm}\left(y_{i j}^{ \pm}\right)^{\beta_{i}}$

subject to:

$$
\begin{aligned}
& h_{i} x_{i}^{ \pm} \leq \tilde{W}_{i}, \quad \forall j \\
& 0 \leq y_{i j}^{ \pm} \leq x_{i}^{ \pm}, \quad \forall i, j \\
& h_{i}\left(x_{i}^{ \pm}-y_{i j}^{ \pm}\right)=\frac{\widetilde{W}_{i}}{\sum_{i} \widetilde{W}_{i}} Q_{j}^{ \pm}, \text {if } \sum_{i=1}^{m} \widetilde{W}_{i} \geq Q_{j}^{-}, \quad \forall j \\
& h_{i}\left(x_{i}^{ \pm}-y_{i j}^{ \pm}\right)<\frac{\widetilde{W}_{i}}{\sum_{i} \widetilde{W}_{i}} Q_{j}^{ \pm}, \text {if } \sum_{i=1}^{m} \widetilde{W}_{i}<Q_{j}^{-}, \quad \forall j
\end{aligned}
$$

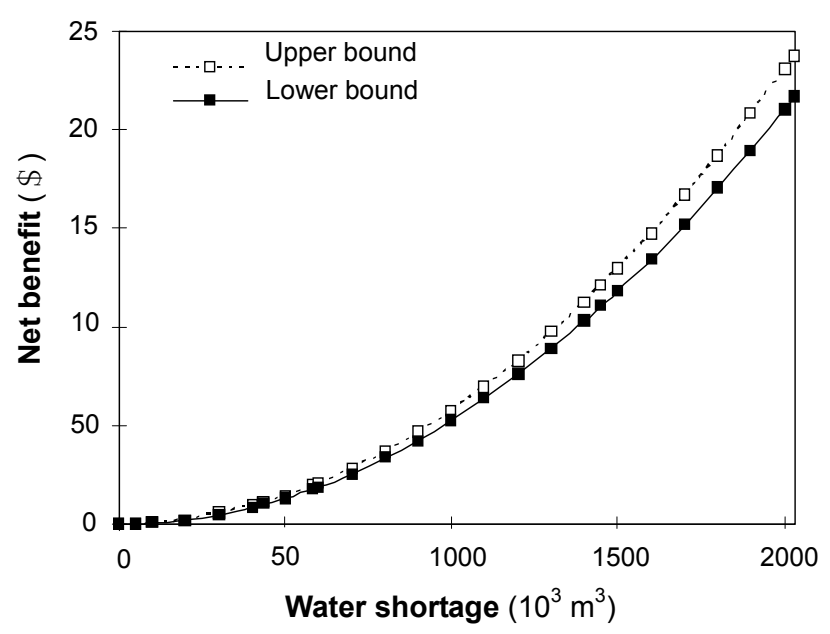

Figure 1. Relationship between net benefit reduction and water shortage.

According to model (5), when water is tradable, the problem can be formulated as follows:

$\operatorname{Max} \bar{\Psi}_{2}^{ \pm}=\sum_{i=1}^{u} h_{i} b_{i}^{ \pm} x_{i}^{ \pm}-\sum_{i=1}^{u} \sum_{j=1}^{v} p_{j} h_{i} d_{i}^{ \pm}\left(y_{i j}^{ \pm}\right)^{\beta_{i}}$

subject to:

$$
\begin{aligned}
& \sum_{i=1}^{u} h_{i} x_{i}^{ \pm} \leq \sum_{i=1}^{m} \tilde{W}_{i}, \quad \forall j \\
& 0 \leq y_{i j}^{ \pm} \leq x_{i}^{ \pm}, \quad \forall i, j \\
& \sum_{i=1}^{u} h_{i}\left(x_{i}^{ \pm}-y_{i j}^{ \pm}\right) \leq Q_{j}^{ \pm}, \quad \forall j
\end{aligned}
$$

where $x_{i}^{ \pm}$is the fixed water-allocation target to farmer $\mathrm{i}\left(\mathrm{m}^{3}\right)$; $y_{i}^{ \pm}$is the amount by which $x_{i}^{ \pm}$is not met; $h_{i}$ is areas of cropped land to farmer i (acre); $b_{i}^{ \pm}$is net benefit to farmer $\mathrm{i}$

Table 3. Data About Cropped Land, Water Permits and Economic Factors

\begin{tabular}{ccccccc}
\hline Farmer & $\begin{array}{c}\text { Water permit for } \\
\text { each farmer } \\
\left(\widetilde{W}_{i} \times 10^{3} \mathrm{~m}^{3}\right)\end{array}$ & $\begin{array}{c}\text { Cropped area for } \\
\text { each farmer }\left(h_{i}\right)\end{array}$ & $\begin{array}{c}\text { Crop water } \\
\text { demand in year } \\
2050\left(x_{i}^{ \pm}\right)\end{array}$ & $\begin{array}{c}\text { Net benefit when } \\
\text { water demand is } \\
\text { satisfied }\left(h_{i} b_{i}^{ \pm}\right)\end{array}$ & $\begin{array}{c}\text { Reduction of net } \\
\text { benefit when water is } \\
\text { not delivered }\left(h_{i} x_{i}^{ \pm}\right)\end{array}$ & $\beta_{i}$ \\
\hline 1 & 5000 & 2800 & {$[1250,1750]$} & {$[98,103.6]$} & $(3.892,4.2]$ & 1.6 \\
2 & 1500 & 1200 & {$[850,1190]$} & {$[334.8,339.6]$} & $(230.9,336.8]$ & 1.0 \\
3 & 4100 & 2000 & {$[1450,2030]$} & {$[132,138]$} & $(10.16,11.14]$ & 1.4 \\
\hline
\end{tabular}


per unit of water allocated; $d_{i}^{ \pm}$is reduction in net benefit to farmer i per unit of water not delivered; all remaining parameters are the same as mentioned in models (4) and (5).

Models (15) and (16) can be transformed into submodels similar as models (7) and (8), respectively. Solutions of these nonlinear submodels were obtained through LINGO optimization program (LINGO, 2003).

\section{Result Analysis and Discussion}

Table 4 presents the solutions obtained through model (15) when water is not tradable. It is indicated that the solutions of water shortage, allocation water, and net benefits are all interval values. The total water allocation target for all farmers is 10.262 million $\mathrm{m}^{3}$, which is less than their total water permits.

Table 5 shows the average net benefit $\left(\bar{\Psi}_{10 p t}^{ \pm}\right)$, net benefit of each farmer $\left(\Psi_{i j(1)}^{ \pm}\right)$, and total net benefit $\left(\sum \Psi_{i j(1)}^{ \pm}\right)$for all farmers when total amount of irrigation water is $Q_{i}^{ \pm}$under probability $p_{i}$ without water trading. It is indicated that the average net benefit $\left(\bar{\Psi}_{1 \text { lopt }}^{ \pm}\right)$to the system would range from $\$ 623,286$ to $\$ 733,735$ under different water allocation schemes. Moreover, the allocation to each farmer during dry seasons would be less than its target, which means that water violation existed and thus penalties paid. For example, when the total water amount would be from 4 to 4.5 million $\mathrm{m}^{3}$, the total net benefits of all farmers would be from $\$ 76,864$ to $\$ 292,687$. However, when the total available water amount would increase, the total net benefit would correspondingly increase and reach its maximum values ranging from $\$ 847,784$ to $\$ 875,224$ eventually.

Table 6 shows obtained solutions through model (16) for the water allocation-target and allocation scheme with water trading. It is indicated that most of the solutions are presented as intervals. The total water-allocation target for all farmers is 10.041 million $\mathrm{m}^{3}$, which is also less than farmers' total water permits.

Table 7 shows the average net benefit $\left(\bar{\Psi}_{2 o p t}^{ \pm}\right)$, net benefit of each farmer $\left(\Psi_{i j(2)}^{ \pm}\right)$, and total net benefits for all farmers $\left(\sum \Psi_{i j(2)}^{ \pm}\right)$when total irrigable water is $Q_{j}^{ \pm}$under probability $p_{i}$ with water trading. It is shown that the average net benefit $\left(\bar{\Psi}_{2 \text { opt }}^{ \pm}\right.$) would range from $\$ 675,978$ to $\$ 749,692$ under different water allocation schemes. For dry seasons, penalties would occur because of water shortage. For example, when the total available water amount would be 6.5 to 7 million $\mathrm{m}^{3}$, the total net benefits for all farmers would range between $\$ 556,541$ and $\$ 658,816$. However, the benefits would increase with increase in total irrigable water and reach their utmost values between $\$ 839,394$ and $\$ 866,393$.

A comparison of Tables 4 and 6 indicates that water would be transferred from farmers 1 and 3 to farmer 2 after trading since farmer 2 is more efficient user. Accordingly, the net benefit of farmer 2 would increase and farmers 1 and 3 decrease after trade. For example, water allocated to farmer 2 would be between $566.038 \times 10^{3}$ and $636.792 \times 10^{3} \mathrm{~m}^{3}$ with corresponding net benefit of $\$ 156,459$ to $\$ 251,896$ without trading when water availability would be 4 to 4.5 million $\mathrm{m}^{3}$; however, allocation water would increase to $1428 \times 10^{3} \mathrm{~m}^{3}$ with associated increased net benefit of $\$ 398,412, \$ 404,124$ after trade. In comparison, water allocation to farmer 3 would be $1547.170 \times 10^{3} \mathrm{~m}^{3}$ to $1740.566 \times 10^{3} \mathrm{~m}^{3}$ with a net benefit of $\$ 24,923, \$ 81,993$ before trade, while this allocation amount would decrease between $797.680 \times 10^{3}$ and $1060 \times 10^{3} \mathrm{~m}^{3}$ corresponding to decreased net benefit (i.e. loss) of $\$-28.292$, - \$3.927. This implies that farmers who contribute water after trading would get compensation from farmers who get water before trading.

Table 8 shows the comparison of the total allocation water and the associated net benefits for all farmers with and without water trading. It is indicated that the water allocation target with trading would be less than the value without trading. However, the average net benefit with trading would be larger than the relevant value without trading. This means that trading would be efficient if reallocations are considered.

Figure 2 presents the relationships between average net benefits and water allocation target with and without trading under different probabilities of water availability. It is shown that the efficiency of water trading would be higher during dry seasons. However, efficiency of trading would not be significant when total water supply would be adequate to all farmers. For example, during low flows, the unitary total net benefits would range from 0.0192 to $0.0650 \$ / \mathrm{m}^{3}$ without trading; however, they would range from 0.0549 to 0.0811 $\$ / \mathrm{m}^{3}$ after trade when the probability water availability would be 0.15 . In comparison, during high flows, the unitary total net benefits would range from 0.0818 to $0.0844 \$ / \mathrm{m}^{3}$ without trading and from 0.0836 to $0.0863 \$ / \mathrm{m}^{3}$ with trading under 0.15 to 0.2 probabilities. This implies that water trading would only have particular implications when there would be shortage of available water. Models (4) and (5) can also be solved by conventional two-stage stochastic nonlinear programming by letting all interval parameters be equal to their mid-values.

The obtained solution is a set of deterministic values. It represents a decision under an input scenario (mid-values for all parameters), and is actually one of many alternatives from the ITSNP. Although further sensitivity analysis can be undertaken for the TSP solution, numerous possibilities exist when many inputs are uncertain. For each possibility, the sensitivity analysis can only provide an individual response to variations of the uncertain inputs. It can hardly reflect interactions among these uncertainties (Huang \& Loucks, 2000).

From the case study, the decreased water allocation target with trading indicates that the cost of water available for other uses such as ecosystem protection can be measured. It should be noticed that releasing water from the agricultural system through water trading would create non-market benefits, such as improved water quality, more water for fish and other aquatic species (Tisdell, 2001).

The case study assumes that relations between crop production and irrigation water are exponent for all three crops. This may not be true in most of real case studies since crop production is determined by not only the availability of irrigation water, but also factors such as weather conditions, fertilizers, and soil types. Since irrigation is the most critical 
Table 4. Water Allocation Targets Without Trading (unit: $10^{3} \mathrm{~m}^{3}$ )

\begin{tabular}{|c|c|c|c|c|}
\hline Farmer & 1 & 2 & 3 & Total \\
\hline$\lambda_{i(1)}$ & 0.91 & 1 & 1 & \\
\hline Target $\left(h_{i} x_{i(1)}^{ \pm}\right)$ & 4774 & 1428 & 4060 & 10262 \\
\hline \multicolumn{5}{|c|}{ Shortage $\left(h_{i} y_{i j(1)}^{ \pm}\right)$} \\
\hline $\mathrm{J}=1$ & {$[2651.358,2887.208]$} & {$[791.208,861.962]$} & {$[2319.434,2512.830]$} & {$[5762,6262]$} \\
\hline $\mathrm{J}=2$ & {$[1472.113,1707.962]$} & {$[437.434,508.189]$} & {$[1352.453,1545.849]$} & {$[3262,3762]$} \\
\hline $\mathrm{J}=3$ & {$[0,528.717]$} & {$[0,154.415]$} & {$[0,578.868]$} & {$[0,1262]$} \\
\hline $\mathrm{J}=4$ & 0 & 0 & 0 & 0 \\
\hline $\mathrm{J}=5$ & 0 & 0 & 0 & 0 \\
\hline \multicolumn{5}{|c|}{ Allocation $\left(A_{i j(1)}^{ \pm}=h_{i}\left(x_{i(1)}^{ \pm}-y_{i j(1)}^{ \pm}\right)\right)$} \\
\hline $\mathrm{J}=1$ & {$[1886.793,2122.642]$} & {$[566.038,636.792]$} & {$[1547.170,1740.566]$} & {$[4000,4500]$} \\
\hline $\mathrm{J}=2$ & {$[3066.038,3301.887]$} & {$[919.811,990.566]$} & {$[2514.151,2707.547]$} & {$[65000,7000]$} \\
\hline $\mathrm{J}=3$ & {$[4245.283,4774]$} & {$[1273.585,1428]$} & {$[3481.132,4060]$} & {$[9000,10262]$} \\
\hline $\mathrm{J}=4$ & 4774 & 1428 & 4060 & 10262 \\
\hline $\mathrm{J}=5$ & 4774 & 1428 & 4060 & 10262 \\
\hline
\end{tabular}

Table 5. Net Benefit for Each Farmer Without Trading Under Different Flow (unit: $\$ 10^{3}$ )

\begin{tabular}{lcccc}
\hline \multicolumn{1}{c}{ Probability } & Farmer 1 & Farmer 2 & Farmer 3 & $\sum_{i=1}^{u} \Psi_{i j(1)}^{ \pm}$ \\
\hline$p_{1}=0.15$ & {$[-104.518,-41.202]$} & {$[156.459,251.896]$} & {$[24.923,81.993]$} & {$[76.864,292.687]$} \\
$p_{2}=0.2$ & {$[54.687,97.694]$} & {$[255.763,319.962]$} & {$[144.855,187.024]$} & {$[455.305,604.680]$} \\
$p_{3}=0.3$ & {$[160.829,190.960]$} & {$[355.068,404.124]$} & {$[236.839,280.140]$} & {$[746.569,875.224]$} \\
$p_{4}=0.2$ & {$[181.412,190.960]$} & {$[398.412,404.124]$} & {$[267.960,280.140]$} & {$[847.784,875.224]$} \\
$p_{5}=0.15$ & {$[181.412,190.960]$} & {$[398.412,404.124]$} & {$[267.960,280.140]$} & {$[847.784,875.224]$} \\
Average & {$[105.153,137.483]$} & {$[320.586,364.457]$} & {$[197.547,231.795]$} & \\
\hline \multicolumn{5}{c}{ Average net benefit $\Psi_{1 \mathrm{opt}}^{ \pm}=[623.286,733.735]$} \\
\hline
\end{tabular}


Table 6. Water Allocation Targets With Trading (unit: $10^{3} \mathrm{~m}^{3}$ )

\begin{tabular}{|c|c|c|c|c|}
\hline Farmer & 1 & 2 & 3 & Total \\
\hline$\lambda_{i(2)}$ & 0.7523 & 1 & 1 & \\
\hline Target $\left(h_{i} x_{i(2)}^{ \pm}\right)$ & 4553 & 1428 & 4060 & 10041 \\
\hline \multicolumn{5}{|c|}{ Water shortage $\left(h_{i} y_{i j(2)}^{ \pm}\right)$} \\
\hline $\mathrm{J}=1$ & {$[2539.600,2778.916]$} & 0 & {$[3000,3262.320]$} & {$[5539.600,6041.236]$} \\
\hline $\mathrm{J}=2$ & {$[1537.200,1777.048]$} & 0 & {$[1502,1764]$} & {$[3039.200,3541.048]$} \\
\hline $\mathrm{J}=3$ & {$[0,623.392]$} & 0 & {$[0,417.820]$} & {$[0,1041.212]$} \\
\hline $\mathrm{J}=4$ & 0 & 0 & 0 & 0 \\
\hline $\mathrm{J}=5$ & 0 & 0 & 0 & 0 \\
\hline \multicolumn{5}{|c|}{ Allocation $\left(A_{i j(2)}^{ \pm}=h_{i}\left(x_{i(1)}^{ \pm}-Y_{i j(2)}^{ \pm}\right)\right)$} \\
\hline $\mathrm{J}=1$ & {$[1774.304,2013.620]$} & 1428 & {$[797.680,1060]$} & {$[4000,4500]$} \\
\hline $\mathrm{J}=2$ & {$[2776.172,3016.020]$} & 1428 & {$[2296.000,2558]$} & {$[6500,7000]$} \\
\hline $\mathrm{J}=3$ & {$[3929.828,4553.220]$} & 1428 & {$[3642.180,4060]$} & {$[9000,10041]$} \\
\hline $\mathrm{J}=4$ & 4553 & 1428 & 4060 & 10041 \\
\hline $\mathrm{J}=5$ & 4553 & 1428 & 4060 & 10041 \\
\hline
\end{tabular}

Table 7. Net benefit for each farmer with trading under different flow level (unit: $\$ 10^{3}$ )

\begin{tabular}{ccccc}
\hline Probability & Farmer 1 & Farmer 2 & Farmer 3 & $\sum_{i=1}^{u} \Psi_{i j(2)}^{ \pm}$ \\
\hline$p_{1}=0.15$ & {$[-96.458,-35.042]$} & {$[398.412,404.124]$} & {$[-28.292,-3.927]$} & {$[219.663,365.155]$} \\
$p_{2}=0.2$ & {$[38.265,82.394]$} & {$[398.412,404.124]$} & {$[119.865,172.298]$} & {$[556.541,658.816]$} \\
$p_{3}=0.3$ & {$[146.452,182.129]$} & {$[398.412,404.124]$} & {$[248.244,280.140]$} & {$[793.107,866.393]$} \\
$p_{4}=0.2$ & {$[173.022,182.129]$} & {$[398.412,404.124]$} & {$[267.960,280.140]$} & {$[839.394,866.393]$} \\
$p_{5}=0.15$ & {$[173.022,182.129]$} & {$[398.412,404.124]$} & {$[267.960,280.140]$} & {$[839.394,866.393]$} \\
Average & {$[97.678,129.606]$} & {$[398.412,404.124]$} & {$[179.889,215.961]$} & \\
\hline \multicolumn{5}{c}{ Average net benefit $\bar{\Psi}_{2 \text { opt }}^{ \pm}=[675.978,749.692]$} \\
\hline
\end{tabular}


Table 8. Net benefit per unit water allocated

\begin{tabular}{lcccc}
\hline Probability & $\begin{array}{c}\text { Total water allocated } \\
\text { without trading }\left(10^{3} \mathrm{~m}^{3}\right)\end{array}$ & $\begin{array}{c}\text { Total water allocated } \\
\text { with trading }\left(10^{3} \mathrm{~m}^{3}\right)\end{array}$ & $\begin{array}{c}\text { Unitary benefit prior } \\
\text { trade } R_{j(1)}^{ \pm}\left(\$ / \mathrm{m}^{3}\right)\end{array}$ & $\begin{array}{c}\text { Unitary benefit after } \\
\text { trade } R_{j(2)}^{ \pm}\left(\$ / \mathrm{m}^{3}\right)\end{array}$ \\
\hline$P_{1}=0.15$ & {$[4000,4500]$} & {$[4000,4500]$} & {$[0.0192,0.0650]$} & {$[0.0549,0.0811]$} \\
$P_{2}=0.2$ & {$[6500,7000]$} & {$[6500,7000]$} & {$[0.0700,0.0864]$} & {$[0.0856,0.0941]$} \\
$P_{3}=0.3$ & {$[9000,10262]$} & {$[9000,10041]$} & {$[0.0830,0.0853]$} & {$[0.0881,0.0863]$} \\
$P_{4}=0.2$ & 10262 & 10041 & {$[0.0818,0.0844]$} & {$[0.0836,0.0863]$} \\
$P_{5}=0.15$ & 10262 & 10041 & {$[0.0818,0.0844]$} & {$[0.0836,0.0863]$} \\
Average & 10262 & 10041 & {$[0.0607,0.0715]$} & {$[0.0673,0.0747]$} \\
\hline
\end{tabular}

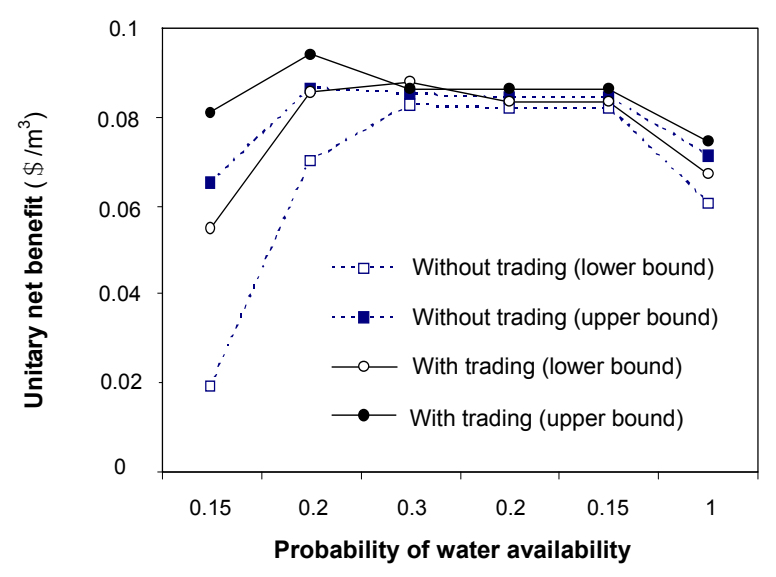

Figure 2. Variation of unitary net benefits under different probabilities of water availability..

factor for crop production in arid and semi-arid regions, the made assumption is reasonable.

Although the developed model is tested with a semihypothetical case, obtained results have demonstrated that the proposed approach is applicable to real-world problems. The ITSNP modeling approach can effectively tackle problems with nonlinear relationships and uncertainties in the form of intervals and probabilities. Moreover, it provides linkage between predefined policies and their economic implications.

\section{Conclusions}

(1) In this study, an inexact two-stage stochastic nonlinear programming (ITSNP) model is presented for analyzing the efficiency of water trading and its impacts on water management within an agricultural system under uncertainty.

(2) The ITSNP is derived by incorporating nonlinear programming within an ITSP optimization framework. The ITSNP improves upon conventional nonlinear programming, two-stage stochastic programming, and interval-parameter programming approaches. It can reflect not only nonlinearity of problems, but also allows uncertainties expressed as probability distributions and discrete intervals. Moreover, ITSNP provides a linkage between the predefined policies and the associated economic implications due to violation of these policies.

(3) The developed model is applied to a case study of water resources management with and without water trading schemes. The obtained results indicate that water trading is efficient for water reallocation during dry seasons when there is a shortage of available water. Moreover, it is found that water trading is a suitable method for adaptation to climate change impacts under scarcity of available water.

(4) Although ITSNP modeling study is the first attempt for adaptation to climate change through water trading, the results suggest that this nonlinear-hybrid technique is applicable to other problems that involve nonlinearities, uncertainties, and policies.

\section{References}

Anderson, L.E. (1968). A mathematical model for the optimization of a waste management system, in SERL Report No. 68-1, Sanitary Engineering Research Laboratory, University of California, Berkeley, CA, USA,.

Anderson, T.L. (1983). Water Crisis: Ending the Policy Drought, Cato Institute, Washington, DC, USA.

Becker, N., Zeitouni, N. and Shechter, M. (1996). Reallocating water resources in the Middle East through market mechanisms. Water Resour. Dev., 12(1), 17-32.

Beraldi, P., Grandinetti, L., Musmanno, R. and Triki, C. (2000). Parallel algorithm to solve two-stage stochastic linear programs with robustness constrains. Parallel Comput., 26, 1889-1908.

Beuhler, M. (2003). Potential impacts of global warming on water resources in southern California. Water Sci. Technol., 47, 165-168.

Birge, J.R. (1985). Decomposition and partitioning methods for multistage stochastic linear programs. Oper. Res., 33, 989-996.

Birge, J.R. and Louveaux, F.V. (1988). A multicut algorithm for two-stage stochastic linear programs. Eur. J. Oper. Res., 34, 384-392.

Brennan, D. and Scoccimarro, M. (1999). Issues in defining property rights to improve Australian water markets. Aust. J. Agric. Resour. Econ., 43, 69-89. 
Chiew, F.H.S. and McMahon, T. (2002). Modeling the impacts of climate change on Australian streamflow. Hydrol. Process., 16(6), 1235-1245.

Dai, L., Chen, C.H. and Birge, J.R. (2000). Convergence properties of two-stage stochastic programming. J. Optimiz. Theory Appl., $106,489-509$

Dales, J.H. (1986). Pollution, Property Rights and Prices, University of Toronto Press, Toronto, Canada.

Darby-Dowman, K., Barker, S., Audsley, E., et al. (2000). A two-stage stochastic programming with recourse model for determining robust planting plans in horticulture. J. Oper. Res. Soc., 51(1), 83-95.

Dragun, A.K. and Gleeson, V. (1989). From water law to transferability in New South Wales. Nat. Resour. J., 29, 645-661.

Edirisinghe, N.C.P. and Ziemba, W.T. (1994). Bounds for two-stage stochastic programs with fixed resources. Math. Oper. Res., 19, 292-313.

Eheart, J.W., Wildermuth, A.J. and Herricks, E.E. (1999). Effects of climate change and irrigation on criterion low streamflows used for determining total maximum daily loads. J. Am. Water Resour. Assoc., 35(6), 1365-1372.

Eiger, G. and Shamir, U. (1991). Optimal operation of reservoirs by stochastic programming. Eng. Optimiz., 17, 293-312.

Frederick, K.D. and Schwarz, G.E. (1999). Socioeconomic impacts of climate change on U.S. water supplies. J. Am. Water Resour. Assoc., 35(6), 1563-1583.

Gassmann, H.I. (1990). MSLIP: A computer code for the multistage stochastic linear programming problem. Math. Program., 47, 407-423.

Herrington, R., Johnson, B. and Hunter, F. (1997). Canada Country Study: Climate Impacts and Adaptation, Volume 3: Responding to Global Climate Change in the Prairies, Environment Canada.

Huang G.H. and Loucks, D.P. (2000). An inexact two-stage stochastic programming model for water resources management under uncertainty. Civ. Eng. Environ. Syst., 17, 95-118.

Huang, G.H. and Moore, R.D. (1993). Grey linear programming, its solving approach, and its application to water pollution control. Int. J. Syst. Sci. (Taylor \& Francis), 24(1), 159-172.

ICDC (2003). http://www.irrigationsaskatchewan.com/.

Kall, P. (1979). Computational methods for solving two-stage stochastic linear programming problems. Z. Angew. Math. Phys., $30,261-271$.

Landry, C. (1998). Market transfers of water for environmental protection in the Western United State. Water Policy, 1, 457-469.

Lettenmaier, D.P., Wood, A.W., Palmer, R.N., Wood, E.F. and Stakhiv, E.Z. (1999). Water resources implications of global warming: A U.S. regional perspective. Clim. Change, 43(3), 537-579.

LINGO (2003). http://www.lindo.com.

Loucks, D.P., Stedinger, J.R. and Haith, D.A. (1981). Water Resource Systems Planning and Analysis, Prentice-Hall, Englewood Cliffs, NJ, USA.

Louveaux F.V. (1980). A solution method for multistage stochastic programs with recourse with application to an energy investment problem. Oper. Res., 28(4), 889-897.

Lustig I.J., Mulvey, J.M. and Carpenter, T.J. (1991). Formulating two-stage stochastic programs for interior point methods. Oper. Res., 39, 757-763.

Maqsood, I. and Huang, G.H. (2003). A two-stage interval-stochastic programming model for waste management under uncertainty. $J$ Air Waste Manage. Assoc., 53, 540-552.

Maqsood, I., Yeomans, J.C. and Huang, G.H. (2003). Water resources management under uncertainty: An interval-parameter fuzzy two-stage programming approach. Eur. J. Oper. Res., Paper No. EJOR2002/161, in press.

Merritt, W.S., Alila, Y., Barton, M., Taylor, B. and Cohen, S.J. (2003). Exploring Impacts of Climate Change on the Hydrology of the Okanagan Basin, in Proc. of the Canadian Water Resources Association, Vancouver, BC, Canada.

Michelsen, A.M. (1994). Administrative, institutional and structural characteristics of an active water market. Water Resour. Bull., 30(6), 971-982

Mimikou, M.A., Baltas, E., Varanou, E. and Pantazis, K. (2000). Regional impacts of climate change on water resources quantity and quality indictors. J. Hydrol., 234, 95-109.

Neilsen, D., Smith, S., Koch, W., Frank, G., Hall, J. and Parchomchuk, P. (2001). Impacts of climate change on crop water demand and crop suitability in the Okanagan Valley, BC, in Technical Bulletin 01-15, Pacific Agri-Food Research Centre, Summerland, BC, Canada, pp. 29

Ojo, O., Oni, F. and Ogunkunle, O. (2003). Implications of climatic variability and climate change on water resources availability and water resources management in West Africa. IAHS-AISH Publ., 280, 37-47.

Rosegrant, M.W., Schleyer, R.G. and Yadav, S.N. (1995). Water policy for efficient agricultural diversification: market- based approaches. Food Policy, 20(3), 203-223.

Ruszczynski, A. and Swietanowski, A. (1997). Accelerating the regularized decomposition method for two-stage stochastic linear problems. Eur. J. Oper. Res., 101, 328-342.

Ruszczynski, A. (1993). Parallel decomposition of multistage stochastic programming problems. Math. Program., 58, 201-228.

Saliba, B.C. and Bush, D.B. (1987). Water markets in theory and practice: market transfers, water values and public policy, Westview Press, Boulder, CO, USA.

Sefton, C.E.M. and Boorman, D.B. (1997). Regional investigation of climate change impacts on UK streamflows. J. Hydrol., 195(1-4), 26-44.

Sen, S. (1993). Subgradient decomposition and differentiability of the recourse function of a two stage stochastic linear program. Oper. Res. Lett., 13, 143-148.

Streeter, R. (1997). Tradable rights for water abstraction. J. Chartered Inst. Water Environ. Manage., 11(4), 277-281.

Tisdell, J.G. (2001).The environmental impact of water markets: An Australian case-study. J. Environ. Manage., 62, 113-120.

Topp, V. and McClintock, A. (1998). Water allocations: Efficiency and equity issues. Aust. Commod., 5, 504-510.

Wollmuth, J.C. and Eheart, J.W. (2000). Surface water withdrawal allocation and trading systems for traditionally riparian areas. $J$. Am. Water Resour. Assoc., 36(2), 293-303.

Yoshitomi, Y., Ikenoue, H., Takeba, T. and Tomita, S. (2000). Genetic algorithm in uncertain environments for solving stochastic programming problem. J. Oper. Res. Soc. Japan, 43, 266-290.

Zhao, G. (2001). A Log-Barrier method with Benders decomposition for solving two-stage stochastic linear programs. Math. Program., 90, 507-536. 